\title{
Karaoke Theatre: Channelling Mediated Lives
}

\section{Jennifer Parker-Starbuck}

KEYWORDS karaoke theatre, channeling, headphones, digital, verbatim performance

\section{Abstract}

This essay suggests that a proliferation of headphones appearing in performance contributes to what the author is playfully calling a 'karaoke theatre,' pointing to a channeling of others, allowing them to reverberate alongside the bodies on stage, and creating new modes of storytelling to better understand this historical digitized moment. As seen through case studies of The Wooster Group’s Early Shaker Spirituals, Royal Osiris Karaoke Ensemble’s (ROKE) The Art of Luv, (Part I), and Daniel Fish's A (Radically Condensed and Expanded) Supposedly Fun Thing I'll Never Do Again (After David Foster Wallace), karaoke theatre uses the idea of "channelling through" forms of digital and networked media. It speaks to a reliance on technologies (from LPs to YouTube) to reactivate a story or stories, real or fictitious, it foregrounds a non-virtuosic turn in both life and performance, and it contains within it a desire to circle or loop back to, and bring to the fore, traces of past events and people.

This essay began to take shape for me during January 2015 at several New York festivals. ${ }^{1}$ On every stage it seemed there were headphones, a visible technology on stage that reminded me of the sudden proliferation of screens on stage at the end of the twentieth century. Although headphones have been frequently used in, for example, verbatim theatre, the use in these festival shows moved out of that realm, engaging with digital culture's shifting hybrid processes to produce a convergence of stories that were actual, fictitious, tragic, and

\footnotetext{
${ }^{1}$ Over the past decade in January New York has hosted a cross-section of new international performance works through P.S. 122's COIL Festival, the American Realness Festival at the Abrons Art Center, and the annual Association of Performing Arts Presenters (APAP) meeting, which have coincided with The Public Theatre's longer-running Under the Radar Festival.
} 
mundane. At the same time it pointed to an exploration of the questions of reality of sources and stories emerging from the proliferation and deployment of technological channels (blogs, vlogs, YouTube, social media outlets, and so on) through which we, in a digital culture, experience other lives. The use of headphones through which we channel others signifies a way to harness stories and allow them to reverberate alongside bodies on stage, creating new modes of storytelling to complicate and understand this historical moment. It comes as no surprise that the theatre, society's mirror, or increasingly, as Aneta Mancewicz has put it, society's 'intermedial mirror,' would take on the historical moment in which media preoccupy, entertain, and augment, reflecting back examples in which traces of histories and lives resonate beyond the performance itself. ${ }^{2}$

I am using the term 'karaoke theatre' as a way to respond to a growing trend of performances using modes of mediatised channelling techniques on stage. The term is intended to be evocative, loosely covering a range of performances in which I begin to identify a channelling that is reminiscent of musical karaoke. This essay is not attempting to define a new genre or lay claim to a coinage, but rather to find connections that might help think through the current state of digital performance. Inspired by the channel as a conduit or transmitter that can be either visible (as in a cable) or non-physical (as in a broadcast), I turn to the form of karaoke for its spirit of transmission, here transmitting ideas about the contemporary moment through a performer's body. This essay itself channels pre-digital encounters with media through to their deployment in what has increasingly been called a digital age. The term 'digital' is itself now increasingly vague, and while technically defined by its opposition to analogue in terms of the generation and storage of data in bits as opposed to waves, it has also come to suggest a state of contemporary engagement with technologies

\footnotetext{
${ }^{2}$ Aneta Mancewicz, Intermedial Shakespeares on European Stages (Basingstoke: Palgrave, 2014), Chapter Three. Mancewicz includes an excellent analysis of the intermedial practices of The Wooster Group in their controversial Troilus and Cressida (later called Cry, Trojans!), originally produced in collaboration with the Royal Shakespeare Company.
} 
of life. I use it following the spirit of Steve Dixon's Digital Performance, when Dixon quotes the Gertrude Stein Repertory Theatre's definition of 'digital' as 'a particular way of describing the real world, a specific technique of encoding sensory data (sound, music, movement, sets, costumes, etc.) that allows that information to be communicated, altered, manipulated, and ultimately interpreted in a complex and potentially intelligent matter. It is an enabling concept.' 3 Of course, channelling in theatre can simply be a method of acting with the actor as conduit for a character or individual, best exemplified in the virtuosic performances of Anna Deavere Smith such as Fires in the Mirror, where she brought characters to life across racial, age, and religious lines. When this transmission is further mediated through the use of devices such as headphones, in-ear headsets, or projected text, it resonates with how experimental companies like the Wooster Group, or Goat Island allow source materials to filter through their processes into the performance, whether it was a visible part of the performance or not. The Wooster Group's technique of using media texts undergirding and driving their performance-making may be a starting point for my observances, but what has propelled me to suggest a karaoke theatre is a (perhaps blatant) foregrounding of these techniques now as a style of performance that traces a lineage from analogue to digital, channelling past times and techniques, karaoke-like, into the current moment.

Karaoke, as Kevin Brown describes in his ethnographic study Karaoke Idols, 'means, literally translated, "empty orchestra" . . . The term first came into use to describe music recordings, created without vocals to be used in rehearsal by professional singers' before coming to mean the now recognisable form of public singing. ${ }^{4}$ As Brown acknowledges, 'much of the early development of karaoke was driven by the commercialization of the

\footnotetext{
${ }^{3}$ Steve Dixon, Digital Performance: A History of New Media in Theater, Dance, Performance Art, and Installation (Cambridge; MA: MIT Press), p. xi.

${ }^{4}$ Kevin Brown, Karaoke Idols: Popular Music and the Performance of Identity (Bristol, Chicago:

Intellect, 2015), p. 28.
} 
technology, ${ }^{5}$ and although the word was coined in 1975, it was the deployment of the compact disc (CD) that promulgated the form to a global phenomenon of expression. Brown's book traces karaoke's cultural constructions into specific karaoke bars where he recounts his experiences as a karaoke participant. He makes a compelling case for karaoke as a channelling of identities: 'karaoke performance is a sort of free-floating field of play, in which people can perform their own identities, but, if they want to, they can also try on other identities for size'. ${ }^{6}$ Karaoke becomes, then, performance guided by several possibilities: the technology itself; a performer's memories of a song, performer, time, or place; the audience; the desire to perform something or someone else. It facilitates a hovering between and a looping back to be co-present with a piece of what has come before, but with the potential to activate it anew. As an infrastructure, karaoke provides an interactive model that transitions from the analogue to the more facile digital, and it becomes a template for democratisations that claim to be present in digital culture. It allows the 'amateur' a space to perform, to channel a song or persona, but co-present with the original, leaving traces of one in the other.

Karaoke theatre then, comes into its own as a form or method for harnessing the driving mediated and digital forces of the twenty-first century into a commentary on these very forces. It is growing more difficult to differentiate between the real, the fictitious, the copy, the original, the recorded, the edited, and the augmented, but as we adapt to digitally enabled laptop/smartphone life we are channelled and we channel more information than ever before, and increasingly we are not bothered by these distinctions. This essay frames a moment of transition/transformation, a partial performance history in which these differentiations are being played out and questioned on stage. In the examples that follow it is still possible to distinguish separate strands, layers, or channels through which we mediate other lives in a digital culture.

\footnotetext{
${ }^{5}$ Brown, Karaoke Idols, p.33.

${ }^{6}$ Ibid. p. 122.
} 
With distinct channels of lineage such as musical karaoke and verbatim theatre, what I am calling karaoke theatre traces a pre-digital lineage to produce work that, as I outline below, uses the idea of 'channelling through' forms of digital and networked media (as opposed to more traditional 'unmediated' acting techniques). It speaks to a reliance on technologies (from LPs to YouTube) to reactivate a story or stories, real or fictitious; it foregrounds a non-virtuosic turn in both life and performance (even if some of the work is very skilful); and it contains within it a desire to circle or loop back to, and bring to the fore, traces of past events and people.

\section{Channels of Legacy: Karaoke Source Material}

A body on stage singing along to a recorded score and following a bouncing ball of scrolling text is a back channel for a karaoke theatre in which bodies are guided or driven by, or resonating with recordings of voices, stories, videos, or events. Musical karaoke sets a metaphoric stage for a theatrical form that engages, re-activates, and moves beyond a text. Its attraction may be as a template for a performance of identity in relation to others; it is an encounter with experiences that might produce transformation. Brown reveals that Karaoke’s origins may also be intertwined with theatre:

Interestingly, karaoke may also be partially descended from kabuki performances. One of the most often cited cultural precursors to karaoke is the nagashi, or strolling musicians ... originally developed by a kabuki actor, Miyakoji Bungo-No-Jo ... according to legend, his songs about committing suicide were so powerful that young lovers attempted to emulate them. ${ }^{7}$

\footnotetext{
${ }^{7}$ Brown, Karaoke Idols, p.25.
} 
So it is no surprise that this form, so full of theatricality, would find itself back on stage. In fact, the Spain-UK company Sleepwalk Collective created a piece entitled Karaoke which staged a literal karaoke - words and phrases were projected on the back screen and performers had to follow these directions. ${ }^{8}$ Also like musical karaoke they could interpret the text but the words dictated their actions. One review described it as such:

Obliged (or condemned) to perform until the lines stop appearing, the voices and bodies on stage are disowned and dislocated. The performers aren't playing characters, but they also aren't quite themselves, not simply because we can't ever trust that what they say is what they really mean. ${ }^{9}$

This theatrical version mimics musical karaoke in a play of identity and self - they are not quite playing characters, but they are not quite themselves - and this is the quality that is played out through all the subsequent examples herein, whether the text is performing as scripted directions as in Karaoke, or as a whisper in a performer's ear through the now ubiquitous earphones.

Another channel of legacy for karaoke theatre is the development of 'verbatim' or 'documentary' theatre, which uses actual testimony, archival material, and interviews as a source for its written and performance texts. Although at times drawing on earlier forms of agit-prop performance, this form was furthered and developed by Anna Deavere Smith's onewoman shows in the 1990s, which used direct testimony to channel a cross-section of performance portraits of people affected by specific political events. Deavere Smith’s work showcased a highly virtuosic ability - acting as an embodied conduit for people of all ages,

\footnotetext{
${ }^{8}$ The show was presented at the Battersea Arts Centre in London in 2014. I was unable to see the show but took interest in its literal translation of the idea of karaoke.

${ }^{9}$ Review: Karaoke, Battersea Arts Centre, by Devawn Wilkinson, 2 March 2014

$<$ http://www.ayoungertheatre.com/review-karaoke-battersea-arts-centre-sleepwalk-collective/> [accessed 2 February 2016]
} 
races, religions, and class. Although there are now branches of scholarship around these forms, I use the term 'verbatim theatre' here to denote work broadly created from the direct testimony of actual people about actual events. ${ }^{10}$

The dependency on the equipment/device in verbatim theatre provides strategies or source material that contributes to a karaoke theatre, and Caroline Wake even proposes a subcategory of 'headphone verbatim' theatre, explaining that 'in headphone verbatim, the performance displays not only the source material but also the mechanical device needed to record and repeat that material'. ${ }^{11}$ Although audiences may, after their initial acknowledgment of the headphone mechanism, forget about the presence of the devices in this form of theatre, it importantly signals the veracity of what is being channelled for the audience as much as for the actor, who often strives to replicate the vocal tics, sounds, and tones of the original voices. The devices' presence in performances (both in and out of verbatim theatre) may raise questions about media noise, originality, and what is real, while also potentially claiming more realness through the onstage presence of the original voices. In her discussion of Roslyn Oades's Stories of Love \& Hate, a play responding to the 2005 Cronulla Riots in Sydney, Australia, Wake explains that 'for those who make their work by soliciting stories, it means thinking about how to frame and perform these voices so they sound like signals rather than simply add to the noise.' (83) I will take this point up at the close of this essay, but a concern with how to signal runs through this analysis of karaoke theatre, whether the source texts are political, real, or fictions, or indeed a combination of

\footnotetext{
${ }^{10}$ See for more information, Alison Forsythe and Chris Megson, Get Real: Documentary Theatre Past and Present (Basingstoke: Palgrave, 2011); Will Hammond and Dan Stewart (eds), Verbatim: Techniques in Contemporary Documentary Theatre (London: Oberon Books, 2008); Terry Stoller, Tales of the Tricycle (London, New York: Bloomsbury Methuen Drama, 2013), Carol Martin, Theatre of the Real (Basingstoke: Palgrave, 2013), Anna Deavere Smith, Fires in the Mirror (New York: Penguin/Random House, 1993), Twilight Los Angeles, 1992: On the Road : A Search for American Character (New York: Anchor Books, 1994).

${ }^{11}$ Caroline Wake, 'Headphone Verbatim Theatre: Methods, Histories, Genres, Theories', New Theatre Quarterly, 29 (November 2013), 321-335 (pp. 322-323).
} 
these. Further, Wake makes the point that 'whereas verbatim theatre might bring "voice to the voiceless," headphone verbatim theatre brings a reflexivity to proceedings that encourages the audiences to contemplate how our culture of communication(s) is produced in the first place. ${ }^{12}$ In the examples below I explore beyond the mechanism and open out the channels toward a broader formation of karaoke theatre. By linking the term 'karaoke' with the term 'theatre' in the examples that follow I want to move beyond a literal re-enactment and look at how reactivation of source material, explorations of the amateur (in an age of 'reality'), and simultaneous transmission can draw attention to how we connect, the 'democraticisation' and proliferation of social media, and media noise in a digitally mediatised age.

\section{Vinyl Verbatim: Coming Round Right}

In Early Shaker Spirituals (2014-ongoing) the Wooster Group creates a more literal karaoke theatre than other examples in this essay. As they have in the past, the Wooster Group artists (re-)turn to a record album, and although we don't see them following along to a text, we can hear the original recording - the 1976 LP Early Shaker Spirituals, recorded by the Shaker sisters at the Sabbathday Lake community in Maine - bleeding out from beyond the headphones. This re-activation hovers in space between a reverence for the original and its re-interpretation, and also reflects an oscillation between pre-digital and digital cultures. The physical performances - hands carefully placed on laps, stiff-backed postures, careful and deliberate movements and gestures - becomes a kind of recording technique itself. Wearing twenty-first-century earpieces the performers' bodies, clad in simple Shaker-style cotton dresses with aprons, and their voices, unadorned with any glimmer of training, transported the sisters' songs to the present. Although the production came to life visually in a series of

\footnotetext{
${ }^{12}$ Caroline Wake, 'The Politics and Poetics of Listening: Attending Headphone Verbatim Theatre in Post-Cronulla Australia', Theatre Research International, 39.2July 2014), 82-100 (p. 83).
} 
dances inspired by the record (among other sources), it was the simplicity of the singing through the body that was most affective. The four main women, Frances McDormand, Suzzy Roche, Cynthia Hedstrom, and Wooster Group director Elizabeth LeCompte, sat or stood on stage with minimal movement and gesture, channelling all twenty songs from the album. ${ }^{13}$ The production is subtitled A Record Album Interpretation and it is as described an interpretation - except that in the background the Shakers can still be heard, their real voices filtering faintly through and allowing them to be present even in their disappearance, in a conscious choice to signal a looping back to this unique and diminishing culture. ${ }^{14}$

This production also loops back to the Wooster Group's own pre-digital history. It returns to their earlier productions, ${ }^{15}$ where a record was the source text guiding the devising process. It returns to the company's youth; Valk recounts a visit to the Sabbathday community when she was a twenty-one-year-old assistant to Liz LeCompte. It returns to the company's archives: Valk says that they have had this LP in the company for thirty-five years. ${ }^{16}$ This production is also, as Ben Brantley noted in his review of the piece, a return to the original source, the Shakers:

This channeling of distant voices parallels stories not only of how the songs were passed down among the Shakers but also of how they were received originally, through ghostly visitations and divine afflatus. On a more mundane level, the process evokes

\footnotetext{
${ }^{13}$ In the production, a fifth actor, Bebe Miller, accompanied these women later in the piece and for the dances, along with five young men who only participated in the dances, and one other as narrator. The show is directed by Wooster Group veteran Kate Valk.

${ }^{14}$ The Sabbathday Community is the last remaining community of Shakers, and because of their vow of celibacy the community has gradually reduced.

${ }^{15}$ See HULA (1981), and L.S.D. (...Just the High Points...) (1984).

${ }^{16}$ Discussed in an informal interview with playwright Richard Maxwell. Kate Valk interviewed by

Richard Maxwell, EARLY SHAKER SPIRITUALS, 9 May 2014

$<$ https://www.youtube.com/watch?v=sYD2TJr84gI $>$ [accessed 2 February 2016]
} 
the ways we are subsumed by the music we listen to daily, via the radio or smartphones, as we sing along and start to feel that it is somehow personally ours. ${ }^{17}$

But what he finds mundane (the process of being subsumed by the music we listen to) has, for me, a different reference. This karaoke trope returns me to the record, the vinyl, which for audiophiles has a warmer, richer sound than its digital followers. Vinyl is also making a comeback for its nostalgic qualities, for past times and, perhaps, for memory of the gaps, scratches and atmosphere of translation. Brantley's reading of the most recognisable songs on the Shaker LP, Tis the Gift to be Simple, is one of 'transcendent theatrical performance' and a 'Dionysian spirit,' both relevant responses; however, my reflection on hearing the lyrics 'to turn, turn will be our delight, till by turning, turning, we come round right,' is upon the nostalgic qualities of vinyl.

This performance evoked the memory of a scratched record, stuck in a groove, looping and repeating those few syllables over and over until the arm was physically lifted and moved beyond the scratch. ${ }^{18}$ The loop returns us to the scratched sound which eventually gets written into memory and incorporated into the personal history of the song for the listener. Here, these songs are transmitted anew, acting as a calling out through these past and present voices, to signal perhaps towards new modes of embodied connectivity in a digital age. This karaoke theatre reminds us of the importance of looking back, of history, and of our embodied relations to technologies in the present. Perhaps thirty-five years later, the Wooster Group, like the Shakers, leaves a gift song somewhere between there and here.

\footnotetext{
${ }^{17}$ Ben Brantley, 'Songs of Devotion, Songs of Rapture: “Early Shaker Spirituals”, Plain-Spoken Tribute', New York Times Online, 29 May 2014 $<$ http://www.nytimes.com/2014/05/30/theater/early-shaker-spirituals-plain-spoken-tribute.html? r=0 > [accessed 2 February 2016].

${ }^{18}$ If space allowed, I would be tempted to trace this looping to digital loop carriers that bundle phone lines into digital signals in telephony.
} 


\section{Mix-Tape Mash-Up}

Our ubiquitous cultural experience of the real results from both live and virtual performances of the self and others in a variety of media. Facebook, YouTube, and reality TV serve as personal performance vehicle. ${ }^{19}$

Royal Osiris Karaoke Ensemble, or ROKE (Tei Blow and Sean McElroy), draws attention to a karaoke format first through its name, and by channelling multiple amateur videos through the artists' performances onstage. ${ }^{20}$ The Art of Luv (Part 1), of which I saw an early incarnation (the pair performed it again in the 2016 festival with the title The Art of Luv (Part 1): Elliot) is a mash-up of six or seven different YouTube clips interspersed with segments of gunman Elliot Rodger's self-made videos, all framed by a guided meditation tape. The piece invokes a quality of the old 'mix-tape,' a fading referent in a digital era, a series of recorded songs made often as a gift to thematise or capture a moment shared. Like a mix-tape, this piece is an ordered collision of different aspects of a theme - here circling around attraction, love, and the lack of it - but is also a karaoke theatre that signals a reliance on the current state of multi-channelled and networked technologies and re-performance.

In the piece Blow and McElroy sit side-by-side painted in gold face/body paint, wearing white toga-style robes before a large screen. In the version I saw, the screen was often split so selected clips could be projected alongside a live feed of one of them who was sitting beneath the screen.

[Insert image somewhere here]

Caption: The Art of Luv Photographer: Maria Baranova. Courtesy of Royal Osiris Karaoke Ensemble]

\footnotetext{
${ }^{19}$ Martin, Theatre and the Real, p. 5.

${ }^{20}$ See a video interview with ROKE in CTR's online resource accompanying this special edition.
} 
The performers take turns simultaneously re-performing the people in these videos, from a teenager trading make-up tips after her 'beauty haul,' to self-help clips, to a woman instructing men how to attract women. The clips are all gender stereotypes and about attraction, or the lack of it in the case of Elliot Rodger, the unstable young man who went on a killing spree in California in 2014 over his inability to find a date. ROKE allow us to hear the actual voices in these clips but then mute them as they take over the text, and in a deadpan, reverse lip-synch, vaguely match their spoken voices to the moving mouths on the screens. This is an uncomfortable and at times funny karaoke performance. Blow and McElroy do not attempt to sound or move like the people on the clips (although there are occasional gestures that correspond to the videos). Rather, projected in goldface on the screen, they channel the texts and voices almost mechanically, matter-of-factly reciting the words and balancing out the mundane, stereotyped, insipid and chilling commentaries through their voices.

This kind of karaoke work invokes a twisted sense of what Carol Martin calls the 'Theatre of the Real,' 'a wide range of theatre practices and styles that recycle reality, whether that reality is personal, social, political, or historical.' Her analysis focuses on theatre that participates in, she argues, 'today's addiction to and questioning of the real as it is presented across media and genres. ${ }^{21}$ At a time when a U.S. Presidential candidate is also a reality television personality, questioning the 'real' is perhaps a critical necessity. In The Art of Luv, the addictive quality of the 'real' is also foregrounded by these karaoke-style amateurs broadcasting their 'talent' for whomever will watch, an outcome of our digital encounters.

Through all the clips it is Rodger's story that reverberates, not the insipid details of a young women's latest skinny jeans purchases, even if such moments, spoken by one of the ${ }^{21}$ Ibid. 
actors, bring out the absurdity of these YouTube or vlog channels. At first, especially when juxtaposed with the meditations on love and self-help snippets, Rodger's story seems pitiable, as he laments the fact that he can't seem to attract women though he takes pains to dress nicely and is sophisticated. However, as it dawns on you who he is, and how many people he killed and wounded, his pleas take on a psychopathic ring. I paraphrase: 'look at how fabulous I look, none of the girls pay attention to me.... I am twenty-two year old and I'm a virgin. It is an injustice because I am gorgeous.' Through his story ROKE creates a disturbance in the digital real. Perhaps because the digital doesn't allow for error in the way the analogue tended to, Rodger's story in ROKE's juxtaposed (or what I am calling mix-tape) mash-up of voices produces a noise that interrupts the others.

But what to make of this collection of voices, interspersed by Rodger's manifesto? Like the mix-tape of old, this piece is curated and comprised of clips only the ROKE company has found (for this particular mix) and framed through this piece to make a comment, and its title provides a clue to understand the theme running through the 'songs.' At the end of the barrage of mundane, gendered, psychotic ramblings of amateur selfpromoters it is tempting to understand this piece as a critique of the open technologies pulling these bodies through the channel, or of the pursuit of Internet fame. But by returning to Rodger's story amidst all the others ROKE accentuates the theme of the tape. Unlike the physical object of the vinyl, however, the mix-tape (both as object and analogy) is less physically connected to the object or its authenticity, and lets voices sit beside each other in a cacophony of noise of equal valence and truth (where, as Wake asked earlier, we might find a warning signal in Rodgers) - but with the title, The Art of Luv. The show is advertised on the ROKE website and in press material as 'a group meditation on masculinity, insecurity, and 
longing - performing humanity’s common search for Love as we misunderstand it. ${ }^{\text {,2 }}$ It, more visibly than the Wooster Group's Early Shaker Spirituals, is a reactivation - here of the actual YouTube videos, but without the reverence or energised embodied channelling of the Wooster Group’s performance. Rather, ROKE’s flattening out of the different voices (which themselves read as so much the same) serves to question the ubiquity of these transmissions and a society that is itself invested in a 'new amateurism', more than the particular individuals cited here. While I (hesitatingly) mention Rodger by name, the point is not only to do with the exploration of the amateur in an age of reality television, but with the use of contemporary technical channels (YouTube, vimeo, blogs and vlogs) that seemingly render ‘face-time' available to everyone. However, given its title, what ROKE and this piece might also signal is hope. Perhaps cynical and shorthand ('Luv'), but Blow and McElroy’s mix-tape mash-up provides a space to explore possibilities and problems of karaoke's amateur and democraticised framing.

\section{Digital Devising}

Daniel Fish's A (Radically Condensed and Expanded) Supposedly Fun Thing I'll Never Do Again (After David Foster Wallace) was the initial provocation for this essay. In this piece, five actors wearing over-the-ear headphones sit across a sparse thrust stage covered with bright yellow tennis balls and one by one are activated through the headphones literally and visually to channel a collection of Foster Wallace's stories. Like karaoke performers waiting for their turn to be called to the stage, the actors seem to sit or stand watching until it is their turn. It is hard to tell what is going on because, unlike in the previous two examples, the audience can never directly hear or see what the actor is listening to. Through the programme

\footnotetext{
${ }^{22}$ http://www.royalosiris.com/art-of-luv-part-1-elliot/ [accessed 2 February 2016]
} 
notes we learn that 'A ... Supposedly Fun Thing ... is comprised of a large selection of David Foster Wallace’s stories, essays, and interviews. Today’s performance represents one of a number of possible selections and arrangements of these texts.' ${ }^{23}$ The press material indicates the text is all taken from audio recordings of Foster Wallace himself, and that the recordings are mixed live during the performance. In addition to the seeming randomness of the mixing, a by-product of a digital age, the piece shaped my thinking about karaoke theatre not only because it channelled as closely as possible Foster Wallace's own recorded readings of his stories, but because the performers performed them like songs at a karaoke club, mostly one at a time, and with the tenacity of someone trying to get it right (following along in karaoke can be a difficult task). Fish sits at a mixing desk at the front of the audience, mixing the selections like a DJ or KJ (karaoke jockey, according to Brown) to challenge the performers. Invoking karaoke, Apple’s Garage Band, and digital DIY (do it yourself) sampling, Fish pushes the actors through speed, duration, and possibly pitch. This becomes clear when one actor struggles to keep up, desperately transmitting Foster Wallace’s dense stream of words while squirming physically and contorting herself in the process. The physicality of this exercise is astonishing. One actor runs in place, another raises her arms above her head seemingly in an attempt to concentrate. Words electrify these bodies, not in a reverence of or oscillation with the text as in the Wooster Group’s Early Shaker Spirituals, but as if the words were lighting up inside and bursting to get out.

After observing the physicality of this sampling the stories finally begin to sink in, and Foster Wallace's prose comes to life as we hear his stories from a cruise ship, tales of a tennis player, and clips about his life from interviews. It is on one hand a powerful exercise in

\footnotetext{
${ }^{23}$ Daniel Fish, 'Note', Programme note, A (Radically Condensed and Expanded) Supposedly Fun Thing I'll Never do Again After David Foster Wallace. Under the Radar Festival 2015. The Public Theatre, New York, [January 7-16 2015].
} 
media-driven acting. At what tempo will the words, already profusive, flow? Will it slow down, speed up? Fish explains this process:

Each performer has headphones and is fed Wallace's voice live in rehearsal and performance. S/he tries to get inside his voice, find it, and repeat it. ... What I think makes it theatrical is the effort it takes the actor to reproduce it. That effort can at times be really, almost physically, difficult and-I hope-compelling to witness. It's a real workout for the actor and maybe for the audience as well. And this perhaps mirrors the experience of reading him—-the reader has got to work hard, but in the end it's deeply rewarding. ${ }^{24}$

It is a work out for the audience. We applaud their virtuosity when the actors get it right and have an empathetic response when they can't seem to keep up. But if it is an acting exercise on one hand, is it, on the other, an elegy for a lost life, a lost time? I am reminded again of Martin's 'theatre of the real' here, and her suggestion that it produces moments of disruption that place the original in a different light:

Theatre of the real also claims authenticity based on an original source that is then copied and simulated and never 'for the first time.' As a result of recycling testimony, documents, film, and video and practices that both exploits and disrupts notions of authenticity, theatre of the real often calls the original into question. ${ }^{25}$

The digital, in its perfect bit by bit copy, of course challenges the existence and auratic nature of the original, and this piece raises the spectre of the original - Foster Wallace himself through its karaoke qualities. Foster Wallace's prose is uniquely populated with detail, extra clauses, asides, winding sentences. What little I know of him is through a few stories and perhaps more so through his much discussed suicide. His words are navigated in this piece by

\footnotetext{
${ }^{24}$ Daniel Fish interviewed by Gary Winter, Brooklyn Rail 2 April 2012 $<$ http://www.brooklynrail.org/2012/04/theater/daniel-fisha-radically-condensed-and-expandedsupposedly-fun-thing-ill-never-do-again-after-david-foster-wallace> [accessed 2 February 2016]

${ }^{25}$ Martin, Theatre of the Real, p. 10.
} 
the actors who are challenged, karaoke style, by the person mixing it live: who will be up next? But as the actors are driven to perform, what also resonates is: who will be up, next? The spectre of Foster Wallace's depression and suicide hung over the piece somehow, provoking me to think deeply about channels of communication and the media noise that has changed so many lives - for good and bad. Yet, like ROKE's The Art of Luv, perhaps we are in a climate of exploring the harshness, the mundanity, the proliferation and presence of digital media on stage so we can better understand just what we are encountering. Fish's website provides such a clue: 'Wallace's work, as translated by Daniel Fish and the performers, asks us: how present can we be? How generous in the way we experience the cacophony of our world? ${ }^{26}$ These works might themselves signal, call out, help us to identify something 'real' through the noise in a digital world that attempts to eliminate distortion.

\section{Coda: Encountering Echoes}

As I was finishing this essay I attended Simon McBurney’s The Encounter, which also used headphones, although this time they were worn not only by McBurney but by the entire audience (of approximately 500 when I saw the show at the Barbican Theatre in London). I experienced first-hand a kind of channelling - McBurney’s two-hour performance took place directly in(to) my ears. My encounter with The Encounter was like being inside an echo chamber; the piece was constructed on many levels, inside and outside of his head, and transmitted directly into mine.

The stage could have been that of a Wooster Group production (or maybe just Spalding Gray): sparse, littered with a table with a microphone and cables, bottles of water strewn about, a large speaker stage left and in the centre of the stage a human-height

\footnotetext{
${ }^{26}$ http://www.danielfish.net/portfolio/a-radically-condensed-and-expanded-supposedly-fun-thing-ill-never-doagain-after-david-foster-wallace/ [accessed 2 February 2016]
} 
microphone stand with a head-shaped (and -sized) binaural microphone on top. McBurney draws us in to his story: a multi-layered tale about his creation of the piece itself, which is about a book about a photographer, Loren McIntyre, who is dropped into the Amazon and encounters the Mayoruna - 'a cat people tribe in Brazil,' he tells us. The piece itself has many channels through which we encounter The Encounter: McIntyre's journey as a throughline, interruptions by McBurney’s (recorded, possibly real life) daughter who wakes up many times as he is making the piece, recordings of novelist Petru Popescu discussing McIntyre, and a complex score of sounds and vocal loops both created live and previously recorded (and often purposely left unclear as to which is which) by McBurney through the binaural technology and played through the piece.

The sense of karaoke theatre here goes beyond McBurney's following text on a rolling teleprompter on two large screens behind the stalls (and possibly also on two smaller ones on stage which we couldn't see), and extends to a quality of the amateur - McBurney's character eagerly describes how he is making the piece in his flat, and explains to us how all the tricks work. But McBurney is no amateur and this is a highly virtuosic performance, yet he plays on this as if he is approaching these technologies for the first time and taking us along for the ride. He begins casually, suggesting that we're waiting for some latecomers, and reminding us that we have responsibility for the millions of photos we are taking of everything ('I have more photos just here on my phone of my child than there ever were of me growing up.') This is a piece about storytelling, technologies, and how the past and future are implicated. McBurney tells us, 'We take stories to be real but they are a fiction; tonight is a real story.' He proceeds to expose the mechanisms he will work with: from the binaural head-on-a-stick microphone that give us a sense of surround sound and its ability to trick the brain to think what we hear is real (I instinctively swatted at the faux mosquito sound he plays as an example, and the hairs on my neck raised when he blew into one ear of the 
microphone); to the ability to lower the pitch of his voice to play the part of McIntyre; to the Katie Mitchell-esque creation of sound effects on stage, as he stomps around in a box filled with old video tape to recreate the sound of walking through the grass. The Encounter is about the intimacy of these technologies both for the audience - in our ear - and the characters (McIntyre loses his precious camera to a monkey in the jungle). It is about time (past, future, co-presence); and it is a story about culture and voice (his encounter with the Mayoruna is complicated by a lack of any common language. ${ }^{27}$ McIntyre cannot survive with the tribe as technological man because his presence will destroy the original. This returns me to Wake's provocation on the politics of listening, which asks how theatre-makers can intervene in neoliberal structures without reproducing such structures. We are, she argues (following sociologist Nick Couldry), having a ‘crisis of voice’: ‘more platforms means more producers; more producers means more content; more content means more chaos, making it that much harder to discern the signal from the noise' that has led to a 'crisis of listening. ${ }^{28}$ How do we, as McBurney attempts to do, embrace the possibilities of the media(ted) while also allowing other voices to oscillate across time and space? What are the politics of virtuosic amateurs re-activating and replaying embodied lives of others through their own in performance?

In his 'Foreword' to Chris Salter's Entangled, theatrical auteur Peter Sellers frames Salter's book on technology by reminding readers precisely to remember the many, varied technologies that we have always used to reactivate and engage across temporal and spatial borders:

\footnotetext{
${ }^{27}$ The intimacy of the piece, hearing every sound and breath in your ears, is then expanded to an intimacy by which spectators/listeners can also access the performance in their homes via a live stream of select performances during its run.

${ }^{28}$ Wake, 'The Politics and Poetics of Listening', p. 83.
} 
Indigenous ceremony uses interdependent technologies embroidered with accompanying narratives to touch and enter a synesthetic state of transcendence that invites an evolving community into a shared aura of undifferentiated, imperceptible simultaneities in which every action is part of another action, in which thought and emotion move in ways that are not limited or overdetermined by temporal powers. ${ }^{29}$

Karaoke theatre may provide storytelling in the twenty-first-century with mediatised means through which to remember and re-activate lives and moments. Channelling pasts, presents and futures, realities and fictions, it offers a way to face head-on the complications posed by the relationship of humanity to those very same technologies.

\footnotetext{
${ }^{29}$ Peter Sellars, 'Foreword,' in Entangled: Technology and the Transformation of Performance, by Chris Salter (Cambridge: MIT Press 2010), pp. ix-xii (p. x).
} 